\section{Renal biopsies should be performed whenever treatment strategies depend on renal involvement}

We read with great interest the European League Against Rheumatism/European Renal Association-European Dialysis and Transplant Association guidelines for the management of antineutrophil cytoplasmic antibody (ANCA)-associated vasculitis (AAV). ${ }^{1}$ We strongly support the recommendation of performing a renal biopsy whenever a renal involvement is suspected as the only organ-threatening or life-threatening manifestation. Indeed, we came across several cases of different diseases presenting as AAV which support this recommendation, as exemplified below. An 18-year-old woman self-presented to the emergency department (ED) with abdominal pain, diarrhoea, gross haematuria and fever for the last 5 days. In ED, blood test was normal (serum creatinine $(\mathrm{SCr})$ at $71 \mu \mathrm{mol} / \mathrm{L}(0.8 \mathrm{mg} / \mathrm{dL})$ and normal blood count) except $\mathrm{C}$ reactive protein at $30 \mathrm{mg} / \mathrm{L}$, and urinary test showed haematuria (100 red blood cells/ $\mu \mathrm{L}$ ) with proteinto-creatinine ratio of $1 \mathrm{~g} / \mathrm{g}$. She was referred to the nephrology department 3 days later.

SCr had increased to $124 \mu \mathrm{mol} / \mathrm{L}(1.4 \mathrm{mg} / \mathrm{dL})$ and the results of the ANCA were strongly positive with a cytoplasmic fluorescence $(>1 / 200)$ and an anti-proteinase 3 specificity $(187 \mathrm{U} / \mathrm{mL})$. In front of this rapidly progressive glomerulonephritis with ANCA positivity, the diagnosis of AAV was strongly suspected and we performed an ultrasound-guided transcutaneous renal biopsy followed by three methylprednisolone pulses. The immunofluorescence microscopy revealed diffuse mesangial IgA fluorescence with less intense C3 codeposition. Light microscopy showed expansion of the mesangial matrix without hypercellularity, intratubular erythrocytic casts and no glomerular crescents. This was consistent with the diagnosis of IgA nephropathy with an M0E0S0T0(C0) MEST score (Mesangial hypercellularity, Endocapillary hypercellularity, Segmental glomerulosclerosis, Tubular atrophy/interstitial fibrosis (Crescent)). Acute renal failure was attributed to the intratubular erythrocytic casts and SCr indeed decreased in the following days in spite of a cessation of immunosuppressive drugs. One month later, her blood pressure was normal $(124 / 66 \mathrm{~mm} \mathrm{Hg})$, proteinuria was not significant anymore $(0.11 \mathrm{~g} / \mathrm{g})$ and $\mathrm{SCr}$ was
$80 \mu \mathrm{mol} / \mathrm{L}(0.9 \mathrm{mg} / \mathrm{dL})$. Six months thereafter she was free of any kidney disease manifestation and we discarded the diagnosis of AAV as she had never demonstrated any extrarenal manifestation. The discontinuation of immunosuppressive treatment in this patient was only permitted by the result of the renal biopsy. In addition, Vrtovsnik et $a l^{2}$ reported the case of a patient with simultaneous IgA nephropathy and granulomatosis with polyangiitis (formerly Wegener's granulomatosis) confirming that even when AAV is confirmed urinary abnormalities may be related to another renal disease, which may change the treatment strategy. Therefore, we would recommend the performance of renal biopsy when kidney impairment is the only organ-threatening or life-threatening manifestation even when $\mathrm{AAV}$ was proven.

Gillian Divard, ${ }^{1}$ Aurelie Sannier, ${ }^{2}$ Guillaume Hanouna, ${ }^{1,3}$ Eric Daugas, ${ }^{1,3}$ Francois Vrtovsnik, ${ }^{1,3}$ Jonathan M Chemouny ${ }^{1,3}$

${ }^{1}$ Department of Nephrology, Bichat-Claude Bernard Hospital, DHU Fire, AP-HP, Paris, France

${ }^{2}$ Department of Pathology, Bichat-Claude Bernard Hospital, DHU Fire, AP-HP, Paris, France

${ }^{3}$ Paris Diderot-Paris 7 University, Paris, France

Correspondence to Dr Jonathan M Chemouny, Hopital Bichat-Claude Bernard, DHU Fire, AP-HP, 46 rue Henri Huchard, Paris 75018, France; jonathan.chemouny@ aphp.fr

Competing interests None declared.

Provenance and peer review Not commissioned; internally peer reviewed.

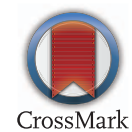

To cite Divard G, Sannier A, Hanouna G, et al. Ann Rheum Dis 2017;76:e27.

Received 7 December 2016

Accepted 10 December 2016

Published Online First 25 January 2017

Ann Rheum Dis 2017;76:e27. doi:10.1136/annrheumdis-2016-210933

\section{REFERENCES}

1 Yates M, Watts RA, Bajema IM, et al. EULAR/ERA-EDTA recommendations for the management of ANCA-associated vasculitis. Ann Rheum Dis 2016;75:1583-94.

2 Vrtovsnik F, Queffeulou G, Skhiri H, et al. Simultaneous IgA nephropathy and Wegener's granulomatosis-overlap or coincidence (the role of renal biopsy). Nephrol Dial Transplant 1999;14:1266-7. 